\title{
PRODUÇÃO DE MUDAS DE MELANCIEIRA SOB DIFERENTES TELAS DE COBERTURA
}

\author{
Márcio Lopes Müller ${ }^{1}$, Jean Paulo de Jesus Tello ${ }^{2 *}$, Janiquelle da Silva Rabelo ${ }^{3}$, Benedito \\ Pereira Lima Neto ${ }^{4}$, Marcelo de Almeida Guimarães ${ }^{5}$

\footnotetext{
${ }^{1}$ Cientista Agrário e do Ambiente. Universidade Federal do Amazonas, Benjamin Constant (AM).

${ }^{2}$ Mestre em Agronomia - Fitotecnia. Universidade Federal do Ceará, Campus do Pici, Fortaleza (CE). *Email: jeanpaulo.tello@gmail.com

${ }^{3}$ Mestranda em Agronomia - Fitotecnia. Universidade Federal do Ceará, Campus do Pici, Fortaleza (CE).

${ }^{4}$ Graduando em Agronomia. Universidade Federal do Ceará, Campus do Pici, Fortaleza (CE).

${ }^{5}$ Professor Doutor do Departamento de Fitotecnia. Universidade Federal do Ceará, Campus do Pici, Fortaleza (CE).
}

RESUMO: A melancieira pertence à família das cucurbitáceas e é cultivada em praticamente todo o território brasileiro, sendo as épocas de temperaturas elevadas as mais indicadas para o cultivo. Na região Norte do Brasil, seu cultivo ocorre principalmente na época da vazante dos rios, sendo cultivadas às margens dos principais recursos hídricos existentes. Com este trabalho objetivou-se avaliar o uso de diferentes telas de cobertura como barreira de proteção ao crescimento e desenvolvimento de mudas de melancieira. Este experimento foi realizado em delineamento inteiramente casualizado, com quatro repetições, sendo avaliadas 50 plantas por repetição. Os tratamentos avaliados foram três tipos de telas de cobertura (T1 - Tela de cor verde com poros de $0,5 \mathrm{~mm}$; $\mathrm{T} 2$ - Tela de cor branca com poros de $0,5 \mathrm{~mm}$; T3 - Tela de cor branca com poros de $0,1 \mathrm{~mm}$ ) e a testemunha (T4 - Sem tela de proteção). Para a caracterização do desenvolvimento das mudas, cinco plântulas de cada tratamento dentro de cada repetição, foram coletadas aleatoriamente aos 20,30, 40 e 50 dias após a semeadura (DAS), sendo as seguintes características avaliadas: número de folhas por planta, comprimento da parte aérea, massa fresca da parte aérea, massa seca da parte aérea, comprimento do sistema radicular, massa fresca do sistema radicular, massa seca do sistema radicular e aspecto das plantas. Baseado nos dados obtidos, conclui-se que o uso de telas de proteção não interfere nas características de desenvolvimento das plantas de melancia aos 50 DAS. O uso de tela branca, com perfurações de $0,1 \mathrm{~mm}$ foi eficiente na produção de mudas com melhor aspecto visual e sem danos aparentes às folhas.

Palavras-chave: Amazônia. Baixa altitude. Baixa latitude. Citrullus lanatus Schard.

\section{PRODUCTION OF WATERMELON SEEDLINGS UNDER DIFFERENT COVERAGE SCREENS}

Cultura Agronômica, Ilha Solteira, v.26, n.3, p.251-264, 2017 


\begin{abstract}
The watermelon belongs to the family Cucurbitaceae and is grown in almost all around Brazil, being the high temperatures the most suitable for its cultivation. In northern Brazil, its cultivation occurs especially during the ebb tide of the rivers, being grown on the banks of the main existing water resources. The objective of this work was to evaluate the use of different cover screens as a barrier to the protection and growth of water melon seedlings. The experiment was conducted in a completely randomized design with four replications and evaluated 50 plants per repetition. The treatments were three types of coverage screens ( $\mathrm{T} 1$ - green screen with pores of $0.5 \mathrm{~mm}, \mathrm{~T} 2$ - white screen with $0.5 \mathrm{~mm}$ pore, T3 - white screen with pores of $0,1 \mathrm{~mm}$ ) and a control (T4 - No protective screen). It characterizes the growth and development of seedlings, five seedlings of each treatment within each repetition, were collected randomly at 20,30, 40 and 50 days after sowing (DAS), with the following characteristics evaluated: number of leaves per plant, shoot length, fresh weight of shoot, shoot dry weight of the root length, fresh weight of roots, dry root weight and appearance of plants. Based on the data obtained, it is concluded that the use of guards does not interfere with growth characteristics and development of watermelon plants at 50 DAS. The use of white screen, with perforations of $0.1 \mathrm{~mm}$ was efficient in the production of seedlings with better visual appearance and without apparent damage the leaves.
\end{abstract}

Key words: Amazon. Low height. Low latitude. Citrullus lanatus Schard.

\title{
INTRODUÇÃO
}

A melancia (Citrullus lanatus) pertence à família das cucurbitáceas e é originária do continente africano (SANTOS et al., 2011). Sua exploração ocorre em muitos países, como Índia, Irã e Estados Unidos (AZEVEDO et al., 2005).

No Brasil é cultivada em praticamente todo o território (PETRY; GUIMARÃES, 2013), sendo as regiões Nordeste e Sul as principais produtoras (IBGE, 2014). Atualmente é uma das mais importantes olerícolas produzidas e consumidas no país, principalmente pelas excelentes condições de desenvolvimento (TORRES, 2007).

O Amazonas merece destaque na região Norte, já que o estado possui a segunda maior área plantada (5.666 ha). No entanto, apesar de ocupar a terceira posição em produção (86 mil toneladas), no ranking da Região, entre os estados que mais produzem esta hortaliça, atrás apenas do Pará e Tocantins (115 e 185 mil toneladas, respectivamente), apresenta baixa produtividade (15,7 $\left.\mathrm{t} \mathrm{ha}^{-1}\right)$ (IBGE, 2014).

Dentre os municípios que compõem o Estado do Amazonas, Benjamin Constant, localizado na mesorregião do Alto Solimões, se destaca na produção de melancia, que é tida como uma das principais fontes de renda dos produtores locais durante os meses de julho a 
outubro. Neste município a melancia é produzida de forma rústica, sendo o modo de implantação e condução dos cultivos, passado através de gerações.

Após levantamento das possíveis causas da baixa produtividade local, vários produtores citaram a baixa taxa inicial de crescimento e desenvolvimento das mudas, bem como a predação de sementes e mudas, por animais, como um dos fatores que mais contribuem para falhas no processo de produção. Além disso, sabe-se também que a condição climática de alta umidade, de baixa altitude e latitude com temperaturas elevadas durante a maior parte do ano, também interferem no sistema de produção. Temperaturas e umidade relativa acima de $35^{\circ} \mathrm{C}$ e $80 \%$, respectivamente, influenciam a formação de flores masculinas, e quando acompanhadas de ventos quentes o fruto terá aumento de transpiração e pressão interna, causando ruptura da casca, além de baixa produtividade e qualidade póscolheita (REZENDE et al., 2017).

Para minimizar estas interferências às plantas, o uso de tela de cobertura tem sido uma prática utilizada e citada por alguns autores. Henrique et al. (2011) usando tela vermelha em mudas de cafeeiro demostrou que nas condições de Lavras (MG) estas proporcionaram maior área foliar, massa de matéria seca da raiz, açúcares solúveis totais e amido na raiz e folha. Os autores relacionam este incremento à percepção de sombra da planta pelo fitocromo. Queiroga et al. (2001) e Bezerra Neto et al. (2005) cultivando alface sob tela branca, ambos em Mossoró (RN), observaram aumentos de fitomassa na planta e retorno financeiro ao produtor, respectivamente. Segundo os autores o ganho de fitomassa se deve às melhores condições de temperatura e luminosidade (aumento no fluxo de fótons) na fase inicial da planta, aumentando a eficiência fotossintética.

Baseado no exposto avaliou-se o uso de diferentes telas de cobertura como barreira de proteção ao crescimento e desenvolvimento de mudas de melancieira em condições de elevada umidade.

\section{MATERIAL E MÉTODOS}

O experimento foi conduzido no período de agosto de 2011 a maio de 2012, em área de produção particular de melancia, localizada no km 14 da BR-307, que liga os municípios de Benjamim Constant e Atalaia do Norte, localizados na Mesorregião do Alto Solimões, Estado do Amazonas.

As sementes de melancieira cultivar Charleston Gray, foram semeadas em copos plásticos de polietileno branco, com capacidade de $180 \mathrm{ml}$. Os recipientes foram preenchidos com substrato preparado com solo de barranco misturado com cama de frango curtida na proporção $1: 1$, que após análise química e física apresentaram as seguintes características: $\mathrm{pH}=6,80 ; \mathrm{P}=50,40 \mathrm{dm}^{-3} ; \mathrm{K}=57,00 \mathrm{mg} \mathrm{dm}{ }^{-3} ; \mathrm{Ca}^{2+}=20,30 \mathrm{cmolc} \mathrm{dm}^{-3}$; $\mathrm{Al}^{3+}=6,90 \mathrm{cmolc} \mathrm{dm}^{-3} ; \mathrm{Mg}^{2+}=0,00 \mathrm{cmolc} \mathrm{dm}^{-3} ; \mathrm{H}+\mathrm{AL}=1,49 \mathrm{cmolc} \mathrm{dm}^{-3} ; \mathrm{CTC}(\mathrm{t})=27,35$ 
cmolc dm ${ }^{-3}$; CTC $(\mathrm{T})=28,84$ cmolc dm$^{-3} ; \mathrm{V}=95,00 \% ; \mathrm{m}=0,00 \%$; Argila $=6 \%$; Silte $=$ $12 \%$; Areia $=82 \%$; Classificação Textural do solo $=$ Franco arenoso.

Após o preenchimento dos recipientes com substrato, procedeu-se a semeadura de duas sementes por copo a uma profundidade de $2 \mathrm{~cm}$, sendo estas cobertas com o mesmo tipo de substrato utilizado para preenchimento. Posteriormente, foi realizado o desbaste, conduzindo uma plântula por copo. Após, os recipientes foram alocados em diferentes tipos de ambiente protegido para avaliação do crescimento e desenvolvimento das mudas.

O delineamento experimental foi inteiramente casualizado, com quatro tratamentos e quatro repetições, sendo conduzidas 50 plantas por parcela experimental. Os tratamentos foram: T1 - Tela de cor verde com poros de $0,5 \mathrm{~mm}$ de abertura; T2 - Tela de cor branca com poros de 0,5 mm de abertura; T3 - Tela de cor branca com poros de 0,1 $\mathrm{mm}$ de abertura; e T4 - Ambiente natural (sem tela de proteção). As telas foram utilizadas como cobertura superior e para o fechamento lateral de estruturas de madeira confeccionadas em dimensões de cerca de $1 \mathrm{~m}^{3}$ cada.

Para a caracterização do crescimento e desenvolvimento das mudas, cinco plântulas de cada parcela experimental foram coletadas aleatoriamente aos 20, 30, 40 e 50 dias após a semeadura (DAS), sendo as seguintes variáveis avaliadas: número de folhas por planta, comprimento da parte aérea $\left(\mathrm{cm} \mathrm{pl}^{-1}\right)$, massa fresca da parte aérea $\left(\mathrm{g} \mathrm{pl}^{-1}\right)$, massa seca da parte aérea $\left(\mathrm{g} \mathrm{pl}^{-1}\right)$, comprimento do sistema radicular $\left(\mathrm{cm} \mathrm{pl}^{-1}\right)$, massa fresca do sistema radicular $\left(\mathrm{g} \mathrm{pl}^{-1}\right)$, massa seca do sistema radicular $\left(\mathrm{g} \mathrm{pl}^{-1}\right)$ e aspecto das plantas. Para esta última variável atribuiu-se notas de 0 a 5 ao aspecto visual das plantas de cada um dos tratamentos avaliados, sendo esta atribuição feita da seguinte maneira: Nota " 0 " - Não era possível visualizar nenhuma parte da planta nos copos plásticos; Nota "1" - Plantas com até $75 \%$ da área foliar faltando; Nota "2" - Plantas com muitos danos aparentes nas folhas, de 50 a 74,9\% área foliar danificada ou faltando; Nota " 3 " - Plantas com danos moderados nas folhas, de 25 a 49,9\% da área foliar danificada ou faltando; Nota "4" - Plantas com danos pequenos nas folhas, abaixo de $24,9 \%$ da área foliar danificada ou faltando; Nota "5" Plantas com aspecto sadio, sem danos aparentes ou ausência de folhas.

Para a obtenção da massa seca das plântulas (parte aérea e raiz), as mesmas foram colocadas em sacos de papel e mantidas em estufa de circulação forçada de ar a temperatura constante de $60^{\circ} \mathrm{C}$ por 48 hs (MOREIRA et al., 2008).

A partir da obtenção dos resultados, ajustaram-se curvas de regressão linear para cada uma das características de crescimento e desenvolvimento avaliadas. Para a variável aspecto das plantas realizou-se análise estatística utilizando-se o procedimento de Scott-Knott ao nível de $5 \%$ de probabilidade para o agrupamento dos tratamentos, para isso, utilizou-se o Software Sisvar ${ }^{\circledR}$ (FERREIRA, 2008).

Cultura Agronômica, Ilha Solteira, v.26, n.3, p.251-264, 2017 


\section{RESULTADOS E DISCUSSÃO}

Não foi observada diferença entre os tratamentos estudados, para a variável número de folhas (NF) por planta aos 40 e 50 DAS, mostrando que a possível redução na luminosidade no ambiente ao longo do tempo, na área de produção de mudas de melancieira, não alterou a quantidade e o tempo de emissão de folhas nas últimas datas de avaliação (Figura 1). Para todos os tratamentos foi possível a obtenção de curvas de regressão linear com percentuais de confiabilidade $\mathrm{R}^{2}$ acima de $99 \%$.

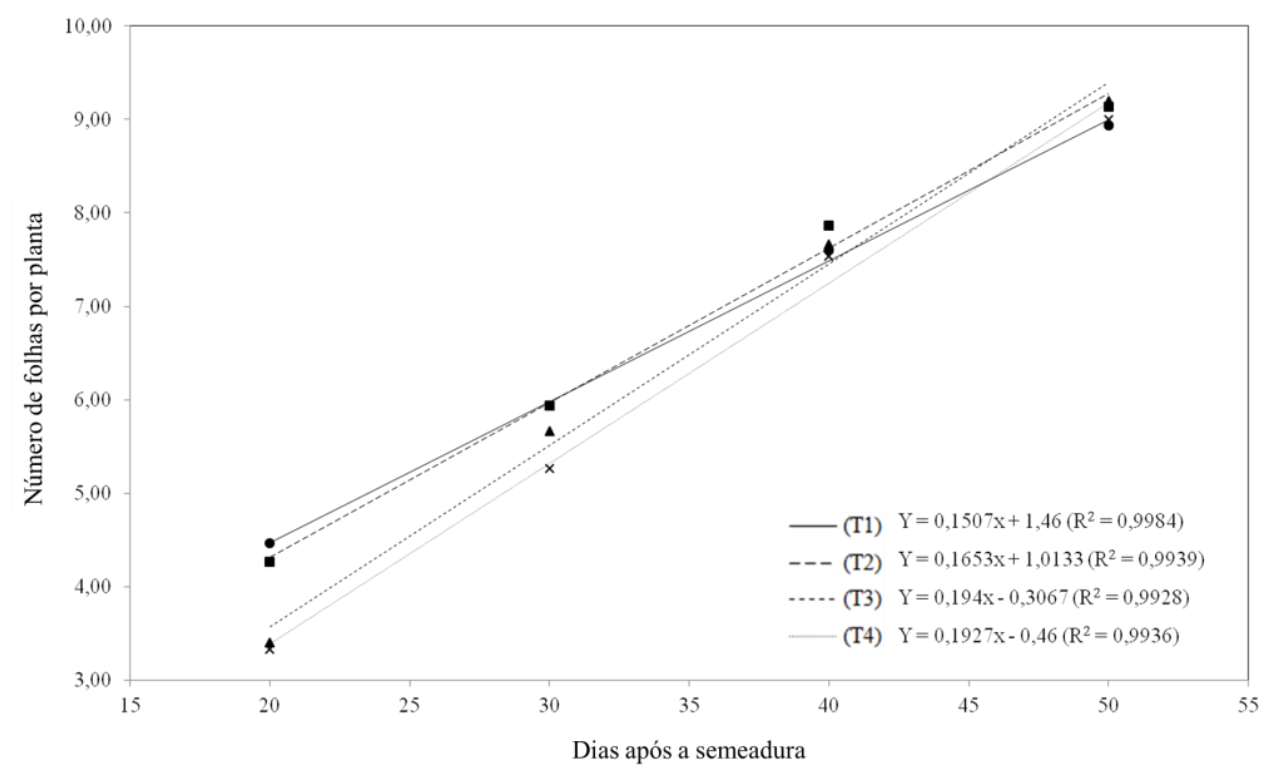

Figura 1. Número de folhas por planta de melancieira submetidas a três diferentes tipos de telas de proteção (T1 - Tela verde com poros de $0,5 \mathrm{~mm}$; T2 - Tela banca com poros de 0,5 $\mathrm{mm}$; T3 - Tela branca com poros de $0,1 \mathrm{~mm}$; e T4 - Ambiente natural) em função do número de dias após a semeadura, na mesorregião do Alto Solimões, Amazonas, 2012.

Costa et al. (2009) trabalhando com mudas de maracujazeiro-amarelo em Aquidauana (MS), observaram melhores resultados de desenvolvimento das plantas para o tratamento cujo fechamento total do viveiro foi realizado com tela de sombreamento de monofilamento, malha para 50\% de sombra em comparação às mudas produzidas em ambiente fechado com tela de sombreamento aluminizada (aluminet ${ }^{\circledR}$ ), malha para 50\% de sombra.

Foi observado o mesmo comportamento para as variáveis comprimento da parte aérea (CPA; Figura 2) e da raiz principal (CRP; Figura 3), onde não houve diferença entre os tratamentos com 40 e 50 DAS. Sendo a diferença observada aos 20 e 30 DAS amenizada ao longo do tempo.

Cultura Agronômica, Ilha Solteira, v.26, n.3, p.251-264, 2017 


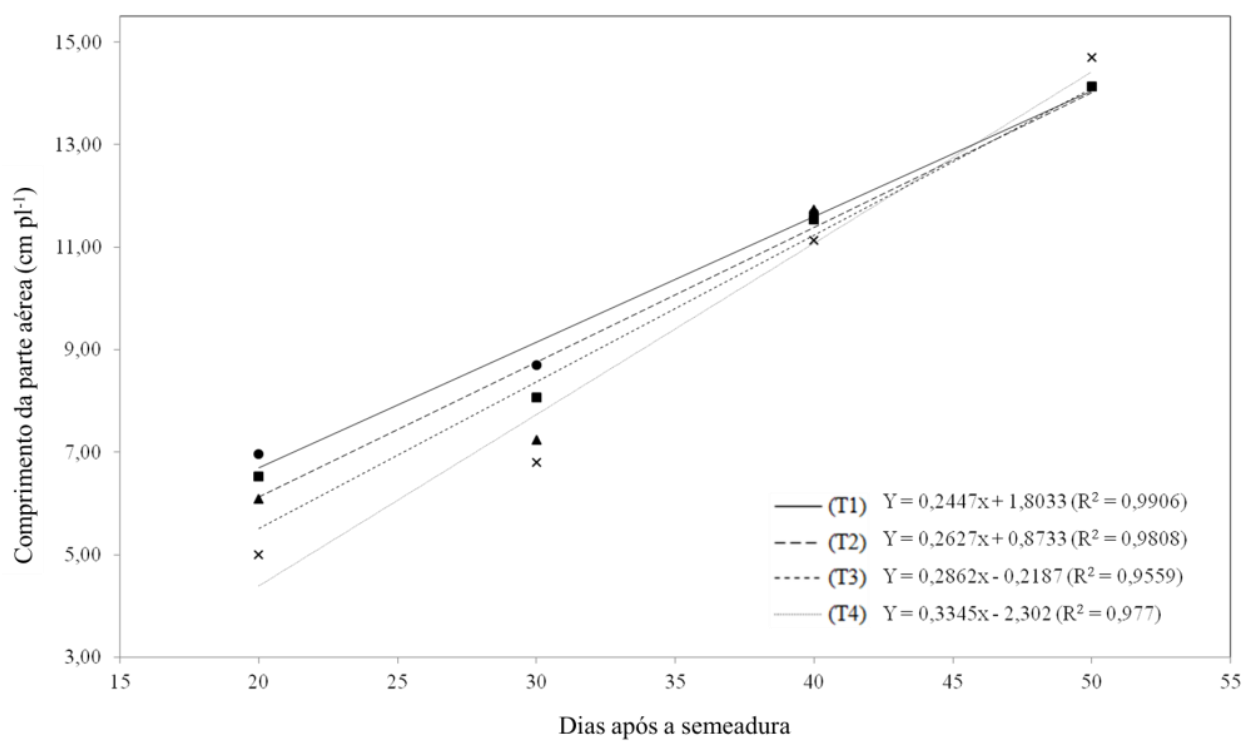

Figura 2. Comprimento da parte aérea $\left(\mathrm{cm} \mathrm{pl}^{-1}\right)$ de plantas de melancieira submetidas a três diferentes tipos de telas de proteção (T1 - Tela verde com poros de 0,5 mm; T2 - Tela banca com poros de $0,5 \mathrm{~mm}$; T3 - Tela branca com poros de 0,1 mm; e T4 - Ambiente natural) em função do número de dias após a semeadura, na mesorregião do Alto Solimões, Amazonas, 2012.

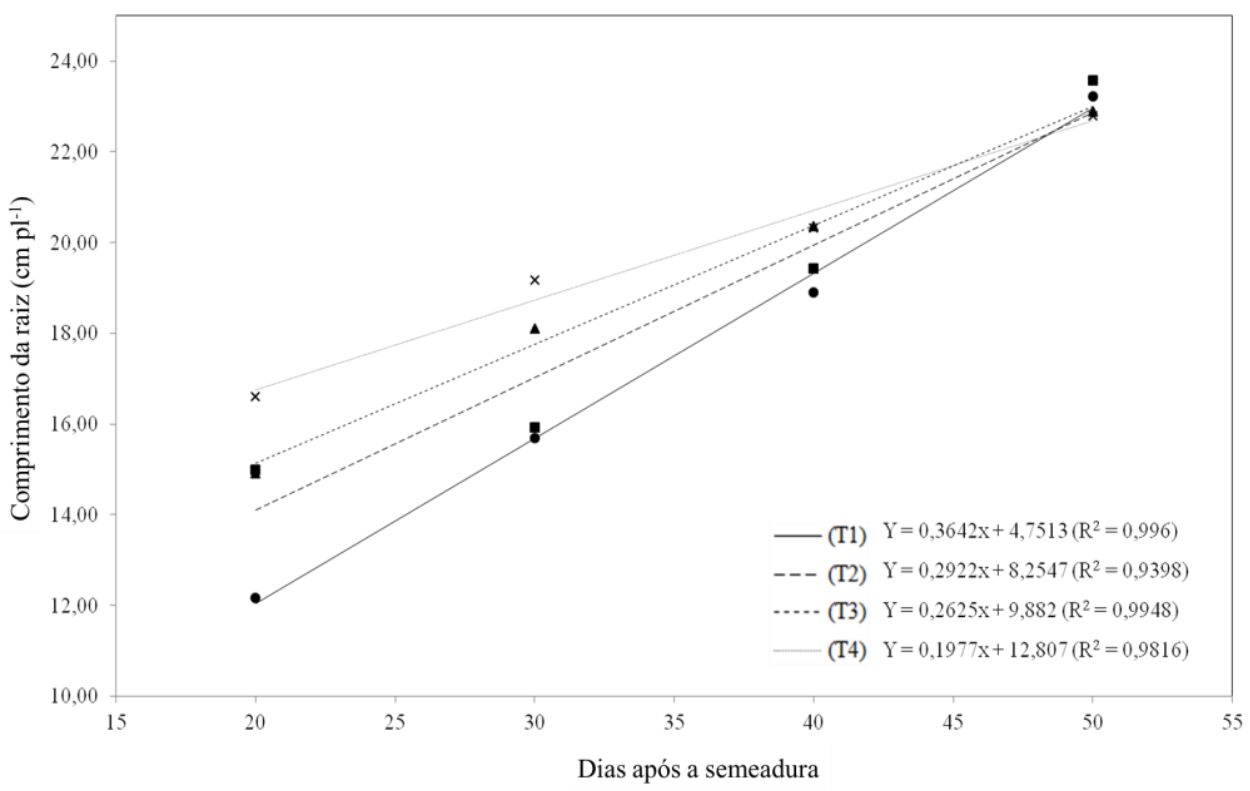

Figura 3. Comprimento do sistema radicular $\left(\mathrm{cm} \mathrm{pl}^{-1}\right)$ de plantas de melancieira submetidas a três diferentes tipos de telas (T1 - Tela verde com poros de 0,5 mm; T2 - Tela banca com poros de 0,5 mm; T3 - Tela branca com poros de 0,1 mm; e T4 - Ambiente natural) em função do número de dias após a semeadura, na mesorregião do Alto Solimões, Amazonas, 2012.

Cultura Agronômica, Ilha Solteira, v.26, n.3, p.251-264, 2017 
Para ambas as características avaliadas pode-se observar crescimento linear ao longo das datas de avaliação. Tal observação proporcionou a obtenção de curvas de regressão lineares para ambas as características. No entanto, com diferentes níveis de confiabilidade.

Diferente do observado neste trabalho, Quinto et al. (2011), avaliando o desenvolvimento de plântulas de melancieira, 'Crimson Sweet', em diferentes ambientes e substratos, observaram valores médios de altura superiores para as plântulas cultivadas em ambientes cobertos com telas sombrite.

Bezerra Neto et al. (2005), avaliando a produtividade de alface em função de condições de sombreamento verificaram diferença entre as plantas cultivadas sob os diferentes tipos de tela de sombreamento, com destaque sendo feito a tela de cor branca. Segundo os pesquisadores a tela de cor branca possibilita maior fluxo de fótons no ambiente, o que favorece a realização de fotossíntese e, por consequência, a produção de fotoassimilados que contribuíram para a maior altura das plântulas produzidas nesta condição.

Para a característica de massa fresca da parte aérea foi observada diferença entre os tratamentos nas datas de 20 e 30 DAS, no entanto, aos 40 e 50 DAS tais diferenças foram reduzidas o que tornou os tratamentos de cobertura e sem cobertura do ambiente de produção de mudas semelhantes (MFPA; Figura 4).

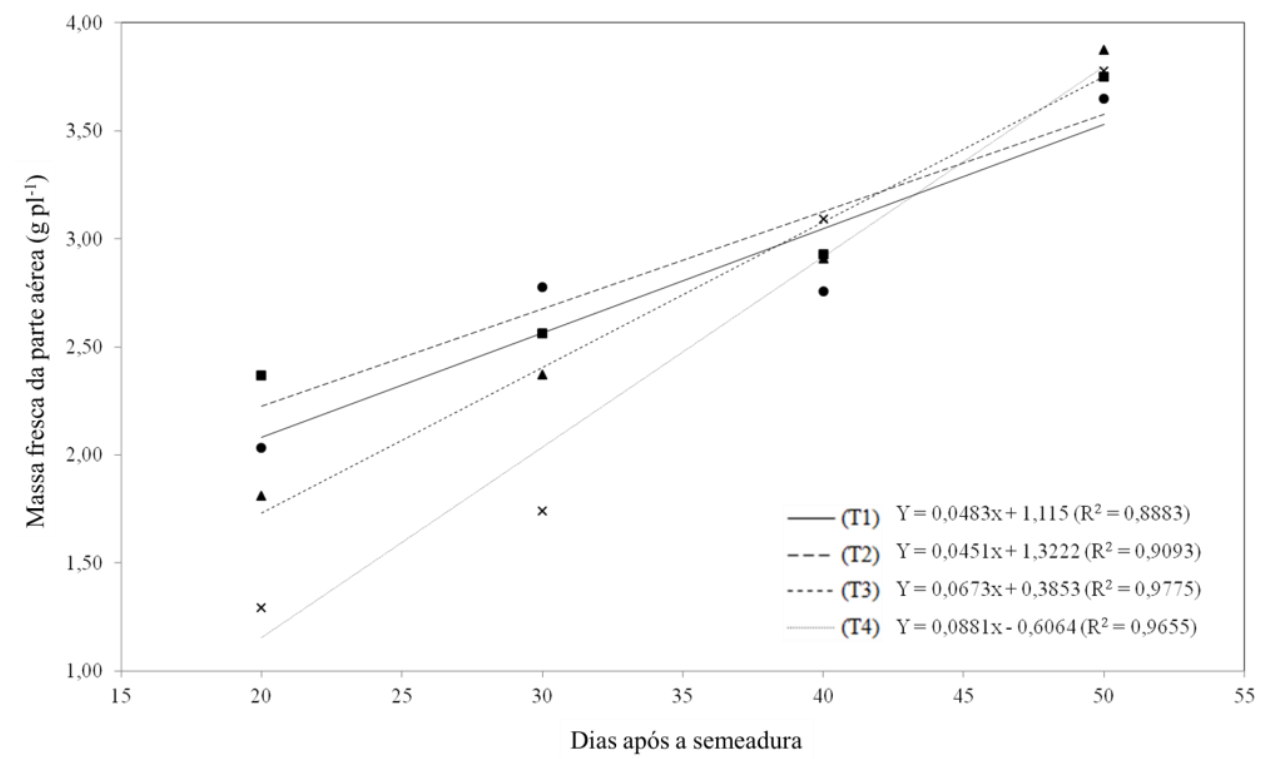

Figura 4. Massa fresca da parte aérea $\left(\mathrm{g} \mathrm{pl}^{-1}\right)$ de plantas de melancieira submetidas a três diferentes tipos de telas de proteção (T1 - Tela verde com poros de $0,5 \mathrm{~mm}$; T2 - Tela banca com poros de $0,5 \mathrm{~mm}$; T3 - Tela branca com poros de $0,1 \mathrm{~mm}$; e T4 - Ambiente natural) em função do número de dias após a semeadura, na mesorregião do Alto Solimões, Amazonas, 2012.

Cultura Agronômica, Ilha Solteira, v.26, n.3, p.251-264, 2017 
Para esta característica também foi possível obter curvas de regressão lineares para todos os tratamentos avaliados, sendo que todas elas apresentaram no mínimo 93,98\% de confiabilidade.

Quanto à massa fresca da raiz principal (MFRP; Figura 5), massa seca da parte aérea (MSPA; Figura 6) e da raiz principal (MSRP; Figura 7), também não foi observada diferença entre os tratamentos dentro das diferentes datas de avaliação realizadas.

Em todos os tratamentos foi possível ajustar curvas de regressão linear com confiabilidade superior a 88,83\% para MFRP, 98,45\% para MSPA e 92,53\% para MSRP.

Queiroga et al. (2001), trabalhando com a produção de mudas de alface em ambiente coberto com tela de cor branca, observou maior produtividade e acúmulo de massa seca dessa cultura. Segundo esses pesquisadores, os melhores resultados obtidos se devem a uma melhor condição do ambiente de produção das mudas, que em geral apresentaram temperatura mais amena e distribuição mais uniforme da luminosidade no ambiente.

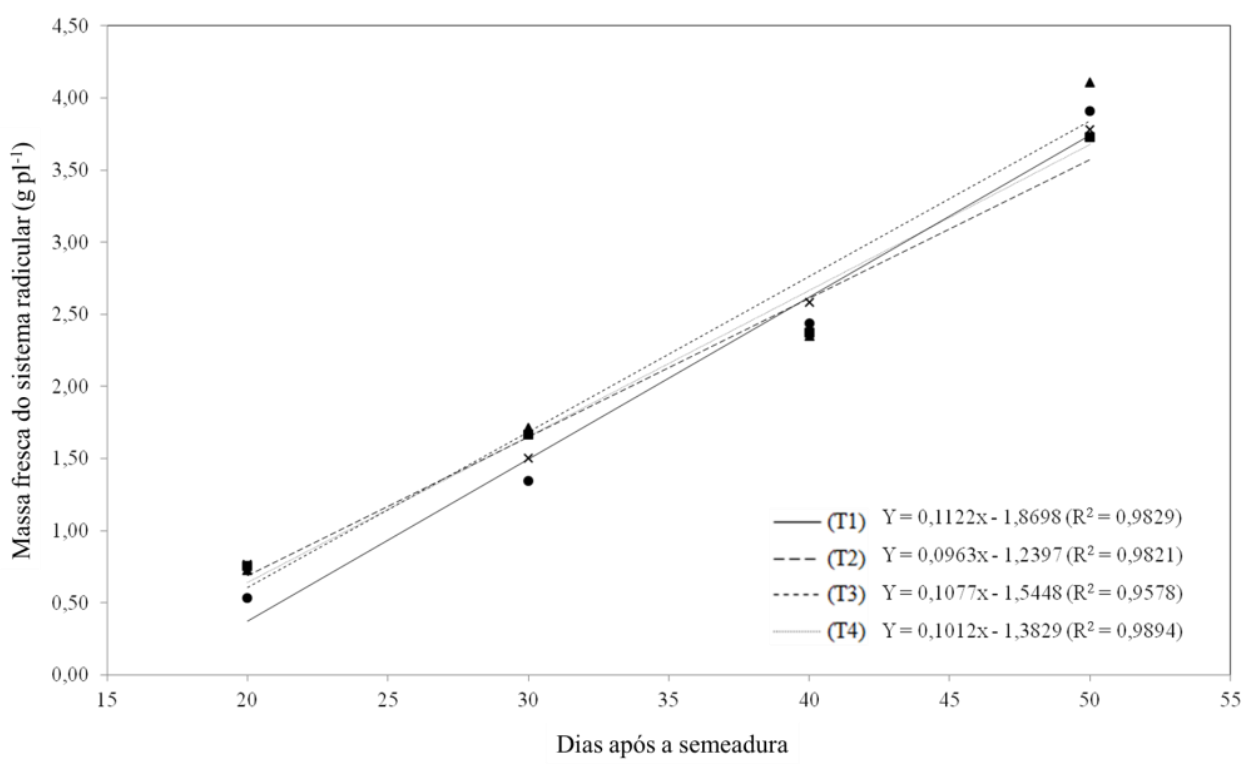

Figura 5. Massa fresca do sistema radicular $\left(\mathrm{g} \mathrm{pl}^{-1}\right)$ de plantas de melancieira submetidas a três diferentes tipos de telas de proteção (T1 - Tela verde com poros de 0,5 mm; T2 - Tela banca com poros de $0,5 \mathrm{~mm}$; T3 - Tela branca com poros de 0,1 mm; e T4 - Ambiente natural) em função do número de dias após a semeadura, na mesorregião do Alto Solimões, Amazonas, 2012.

Cultura Agronômica, Ilha Solteira, v.26, n.3, p.251-264, 2017 


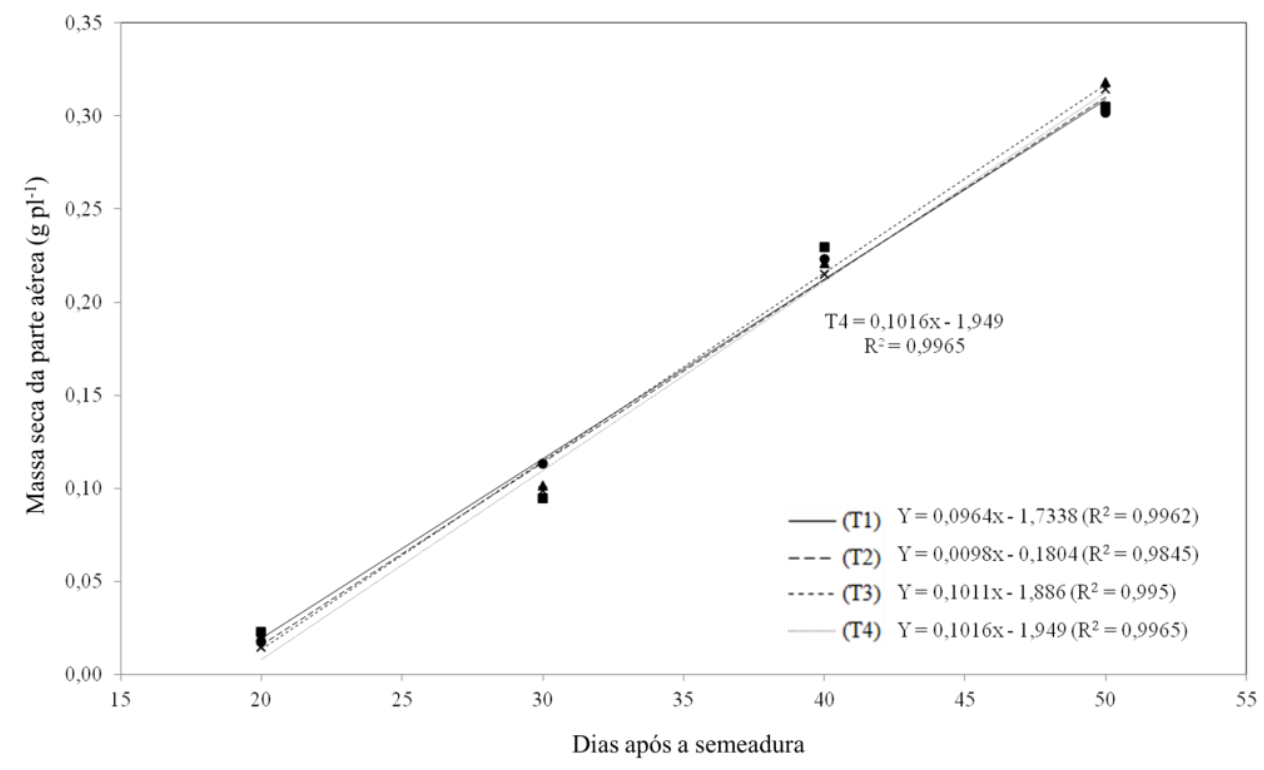

Figura 6. Massa seca da parte aérea $\left(\mathrm{g} \mathrm{pl}^{-1}\right)$ de plantas de melancieira submetidas a três diferentes tipos de telas de proteção (T1 - Tela verde com poros de 0,5 mm; T2 - Tela banca com poros de $0,5 \mathrm{~mm}$; T3 - Tela branca com poros de 0,1 mm; e T4 - Ambiente natural) em função do número de dias após a semeadura, na mesorregião do Alto Solimões, Amazonas, 2012.

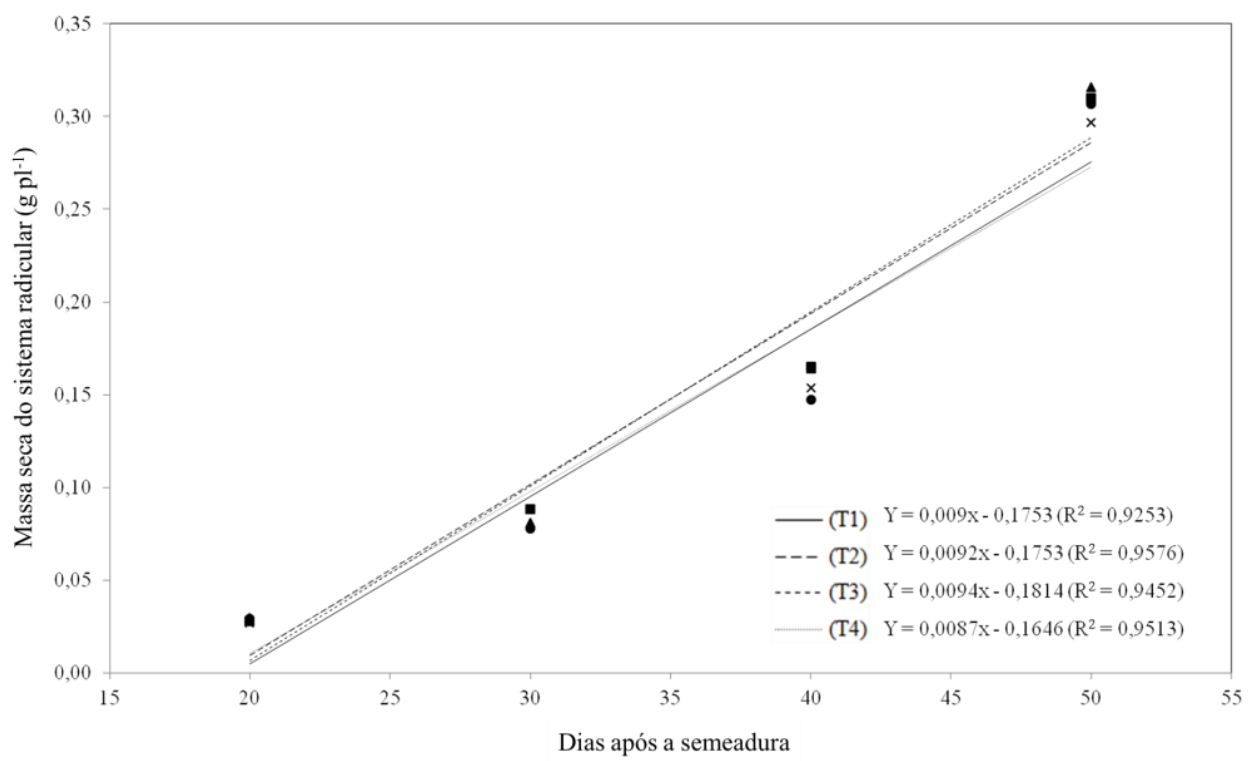

Figura 7. Massa seca do sistema radicular $\left(\mathrm{g} \mathrm{pl}^{-1}\right)$ de plantas de melancieira submetidas a três diferentes tipos de telas de proteção (T1 - Tela verde com poros de 0,5 mm; T2 - Tela banca com poros de $0,5 \mathrm{~mm}$; T3 - Tela branca com poros de 0,1 mm; e T4 - Ambiente natural) em função do número de dias após a semeadura, na mesorregião do Alto Solimões, Amazonas, 2012.

Cultura Agronômica, Ilha Solteira, v.26, n.3, p.251-264, 2017 
Oliveira et al. (2015) avaliando a produção de mudas de melancieira em diferentes ambientes observaram maiores valores de altura de planta e da relação massa seca da parte aérea e massa seca do sistema radicular, das plantas conduzidas em ambiente coberto com telado do tipo Sombrite, em relação àquelas conduzidas em ambiente coberto com filme plástico. Uma possível explicação para os maiores valores obtidos para as plantas desenvolvidas no ambiente com Sombrite ${ }^{\circledR}$ pode estar relacionado a temperatura mais amena nestes ambientes se comparado àquele coberto por filme plástico. Neste último, a temperatura mais elevada pode ter aumentado a taxa de respiração da cultura, bem como sua evapotranspiração, ambos causando uma menor eficiência de assimilação de fotoassimilados e consequentemente, menor produção de massa.

Na Tabela 1, pode-se observar os diferentes valores obtidos para cada variável dentro de cada tratamento, porém sem significância estatística na última data de avaliação, aos 50 dias após a semeadura. Tal resultado é importante quando avaliado em conjunto com a Figura 8. Isso por que, mostra que apesar da provável redução da luminosidade nos ambientes em que se utilizou a tela de sombreamento, esta provavelmente não ocasionou diminuição na taxa de fotossíntese líquida das plantas dos diferentes tratamentos, já que todos apresentaram comprimentos e massas (fresca e seca) da parte aérea e radicular semelhantes.

Tabela 1. Valores médios das características avaliadas em plantas de melancieira submetidas a três diferentes tipos de telas de proteção (T1 - Tela verde com poros de 0,5 mm; T2 - Tela banca com poros de 0,5 mm; T3 - Tela branca com poros de 0,1 mm; e T4 Ambiente natural) aos 50 dias após a semeadura, na mesorregião do Alto Solimões, Amazonas, 2012.

\begin{tabular}{lrrrrc}
\hline Características avaliadas & \multicolumn{1}{c}{$\mathrm{T} 1$} & \multicolumn{1}{c}{$\mathrm{T} 2$} & \multicolumn{1}{c}{$\mathrm{T} 3$} & \multicolumn{1}{c}{$\mathrm{T} 4$} & $\mathrm{CV}(\%)$ \\
\hline Número de folhas & $8,9^{\mathrm{ns}}$ & $9,1^{\mathrm{ns}}$ & $9,2^{\mathrm{ns}}$ & $9,0^{\mathrm{ns}}$ & 3,08 \\
Comprimento da parte aérea $\left(\mathrm{cm} \mathrm{pl}^{-1}\right)$ & $14,1^{\mathrm{ns}}$ & $14,1^{\mathrm{ns}}$ & $14,1^{\mathrm{ns}}$ & $14,7^{\mathrm{ns}}$ & 2,49 \\
Massa fresca da parte aérea $\left(\mathrm{g} \mathrm{pl}^{-1}\right)$ & $3,7^{\mathrm{ns}}$ & $3,8^{\mathrm{ns}}$ & $3,8^{\mathrm{ns}}$ & $3,9^{\mathrm{ns}}$ & 3,00 \\
Massa seca da parte aérea $\left(\mathrm{g} \mathrm{pl}^{-1}\right)$ & $0,3^{\mathrm{ns}}$ & $0,3^{\mathrm{ns}}$ & $0,3^{\mathrm{ns}}$ & $0,3^{\mathrm{ns}}$ & 3,65 \\
Comprimento do sistema radicular $\left(\mathrm{cm} \mathrm{pl}^{-1}\right)$ & $23,2^{\mathrm{ns}}$ & $23,6^{\mathrm{ns}}$ & $22,9^{\mathrm{ns}}$ & $22,8^{\mathrm{ns}}$ & 1,99 \\
Massa fresca do sistema radicular $\left(\mathrm{g} \mathrm{pl}^{-1}\right)$ & $3,9^{\mathrm{ns}}$ & $3,7^{\mathrm{ns}}$ & $4,1^{\mathrm{ns}}$ & $3,8^{\mathrm{ns}}$ & 6,54 \\
Massa seca do sistema radicular $\left(\mathrm{g} \mathrm{pl}^{-1}\right)$ & $0,3^{\mathrm{ns}}$ & $0,3^{\mathrm{ns}}$ & $0,3^{\mathrm{ns}}$ & $0,3^{\mathrm{ns}}$ & 5,31 \\
\hline
\end{tabular}

ns - não significativo pelo teste de agrupamento de Scott-Knott ao nível de $5 \%$ de probabilidade

No entanto, apesar de não terem sido verificadas diferenças no que se refere ao crescimento e desenvolvimento das mudas entre os tratamentos, observou-se clara diferença no aspecto visual das plantas nas datas de 20, 40 e 50 dias após a semeadura. Aos 20 DAS, os tratamentos T1 e T3 foram os que apresentaram mudas com melhor aspecto aparente. Aos 40 e 50 DAS o T3 foi o que apresentou as melhores mudas.

Cultura Agronômica, Ilha Solteira, v.26, n.3, p.251-264, 2017 
Este melhor aspecto observado no tratamento $\mathrm{T} 3$ foi devido principalmente a menor infestação, das plantas, por pragas e/ou danos causados por animais, o que torna este tratamento uma possível ferramenta para a produção de mudas de melhor qualidade, com menores riscos de contaminação, já que menores quantidades de ferimentos nos tecidos podem contribuir de forma significativa para menores índices de infestações.

Apesar das telas de sombreamento utilizadas terem provocado, em média, 15\% da redução de luminosidade dentro das estruturas utilizadas para a produção de mudas, tal redução não foi suficiente para provocar efeitos relacionados ao estiolamento destas, já que não foram observadas diferenças dos tratamentos que se utilizou cobertura e a testemunha (sem nenhuma cobertura). De acordo com Taiz e Zeiger (2013), tal diferença poderia ser observada já que a redução da luminosidade pode provocar o estiolamento da parte aérea com implicações diretas nas características de crescimento das plantas.

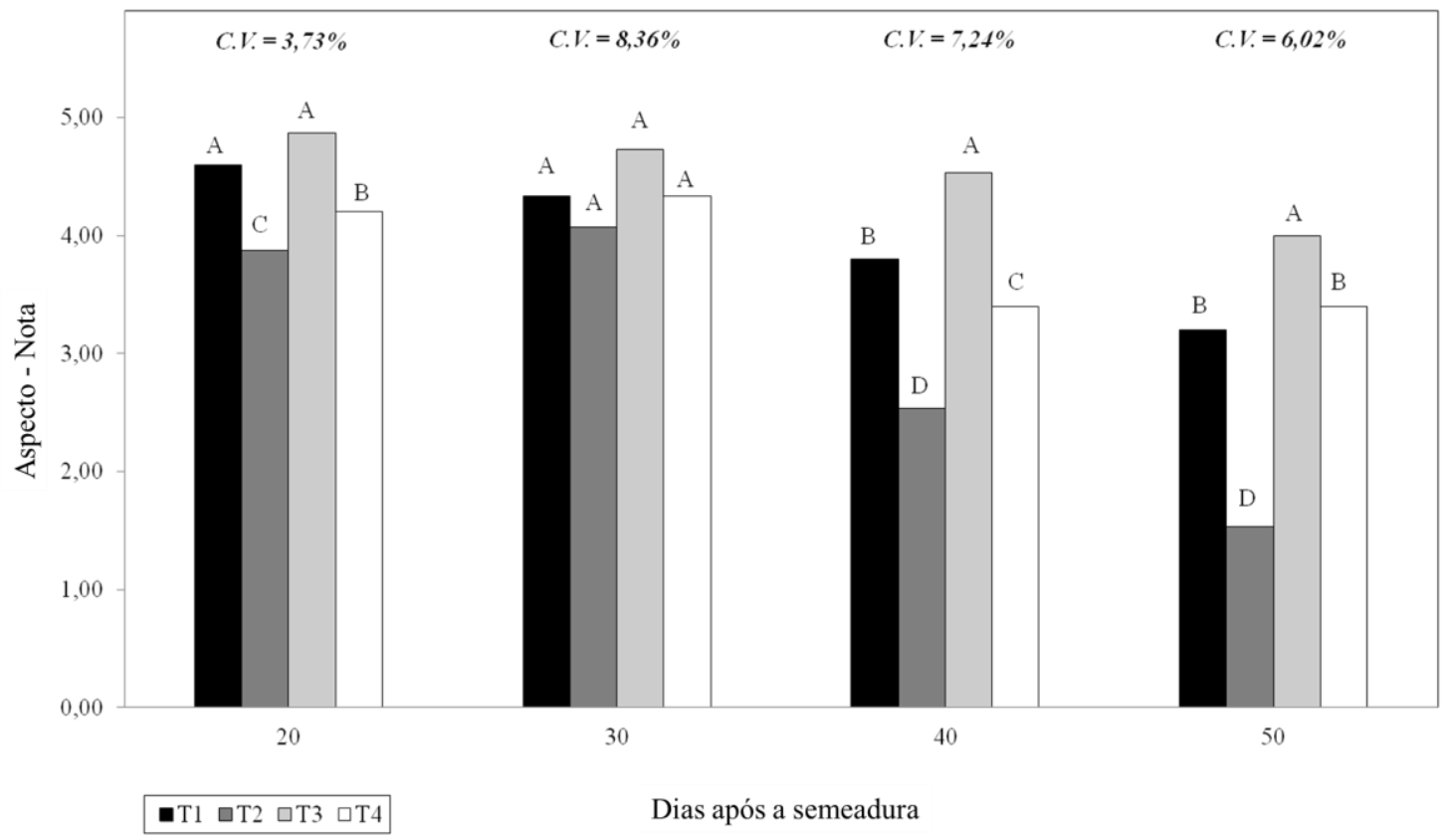

Figura 8. Aspecto em nota atribuído às plantas de melancieira submetidas a três diferentes tipos de telas de proteção (T1 - Tela verde com poros de $0,5 \mathrm{~mm}$; T2 - Tela branca com poros de 0,5 mm; T3 - Tela branca com poros de 0,1 mm; e T4 - Ambiente natural) em função do número de dias após a semeadura, na mesorregião do Alto Solimões, Amazonas, 2012.

\section{CONCLUSÃO}

O uso de telas de proteção não interfere nas características de crescimento e desenvolvimento das plantas de melancieira, após os 40 DAS.

Cultura Agronômica, Ilha Solteira, v.26, n.3, p.251-264, 2017 
Recomenda-se aos produtores de melancieira, que produzem em áreas susceptíveis a predação das sementes ou plantas por insetos ou animais, o uso de ambiente protegido do tipo telado (tela branca e diâmetro de perfurações de $0,1 \mathrm{~mm}$ ), já que o mesmo se mostrou eficiente na produção de mudas com melhor aspecto visual e sem danos aparentes nas folhas em todas as datas de avaliação.

\section{AGRADECIMENTOS}

Ao CNPq, CAPES e FAPEAM, pelas bolsas disponibilizadas aos autores.

\section{REFERÊNCIAS BIBLIOGRÁFICAS}

AZEVEDO, B. M.; BASTOS, F. G. C.; VIANA, T. V. A.; RÊGO, J. L.; D’ÁVILA, J. H. T.; Efeitos de níveis de irrigação na cultura da melancia. Revista Ciência agronômica, Fortaleza, v. $36, \quad$ n. $1, \quad$ p.9-15, 2005. Disponível em: http://www.ccarevista.ufc.br/seer/index.php/ccarevista/article/view/4061/1057. Acesso em: 16 dez. 2015.

BEZERRA NETO, F.; ROCHA, R. C. C.; NEGREIROS, M. Z.; ROCHA, R. H.; QUEIROGA, R. C. F. Produtividade de alface em função de condições de sombreamento e temperatura e luminosidade elevadas. Horticultura Brasileira, Brasília, v. 23, n. 2, p.189192, 2005.2 Disponível em: https://docs.google.com/viewerng/viewer?url=http://www.horticulturabrasileira.com.br/ima ges/stories/23_2/20052325.pdf. Acesso em: 16 dez. 2015.

COSTA E.; RODRIGUES, E. T.; ALVES V. B.; SANTOS L. C. R.; VIEIRA, L. C. R. Efeitos da ambiência, recipientes e substratos no desenvolvimento de mudas de maracujazeiro-amarelo em Aquidauana - MS. Revista Brasileira de Fruticultura, Jaboticabal, v. 31, n. 1, p.236-244, 2009. Disponível em: http://www.scielo.br/pdf/rbf/v31n1/v31n1a33.pdf. Acesso em: 16 dez. 2015.

FERREIRA, D. F. SISVAR: um programa para análises e ensino de estatística. Revista Científica Symposium, Lavras, v. 6, n. 2, p.36-41, 2008. Disponível em: http://www.dex.ufla.br/ danielff/meusarquivospdf/art63.pdf. Acesso em: 16 dez. 2015.

HENRIQUE, P. C.; ALVES, J. D.; DEUNER, S.; GOULART, P. F. P.; LIVRAMENTO, D. E. Aspectos fisiológicos do desenvolvimento de mudas de café cultivadas sob telas de diferentes colorações. Pesquisa Agropecuária Brasileira, Brasília, v. 46, n. 5, p.458-465, 2011. Disponível em: http://www.scielo.br/pdf/pab/v46n5/02.pdf. Acesso em: 04 nov. 2016.

IBGE - Instituto Brasileiro de Geografia e Estatística. Produção Agrícola Municipal: culturas temporárias e permanentes 2014. v. 35. Rio de janeiro: IBGE, 2014. 100 p. 
http://biblioteca.ibge.gov.br/visualizacao/periodicos/66/pam_2014_v41_br.pdf. Acesso em: 16 dez. 2015.

MOREIRA, M. A.; DANTAS, F. M.; SANTOS, C. A. P.; OLIVEIRA, L. M.; MOURA, L.C. Produção de mudas de pimentão com o uso de pó de coco. Revista da Fapese, Aracaju, v. 4, n. 2, p.19-26, 2008. Disponível em: http://www.fapese.org.br/revista_fapese/v4n2/artigo02.pdf. Acesso em: 16 dez. 2015.

OLIVEIRA, A. M. D.; COSTA, E.; REGO, N. H.; LUQUI, L. L.; KUSANO, D. M.; OLIVEIRA, E. P. Produção de mudas de melancia em diferentes ambientes e de frutos a campo. Revista Ceres, Viçosa, v. 62, n. 1, p.087-092, 2015. Disponível em: http://www.ceres.ufv.br/ojs/index.php/ceres/article/view/4220/2038. Acesso em: $16 \mathrm{dez}$. 2015.

PETRY, J. F.; GUIMARÃES, M. A.; O cultivo da melancia no Brasil em números. In: GUIMARÃES, M. A. Produção de Melancia. 1 ed. Viçosa: UFV, 2013. cap. 2, p. 27-43.

QUEIROGA, R. C. F.; BEZERRA NETO, F.; NEGREIROS, M. Z.; OLIVEIRA, A. P.; AZEVEDO, C. M. S. B. Produção de alface em função de cultivares e tipos de tela de sombreamento nas condições de Mossoró. Horticultura Brasileira, Brasília, v. 19, n. 3, p.192-196, 2001. Disponível em: https://docs.google.com/viewerng/viewer?url=http://www.horticulturabrasileira.com.br/ima ges/stories/19_3/20011935.pdf. Acesso em: 16 dez. 2015.

QUINTO V. M.; BELTRAME R. A.; PEREIRA E. O.; CABANÊZ, P. A.; AMARAL, J. F. T. Germinação e desenvolvimento de plântulas de melancieira em diferentes ambientes e substratos. Revista Verde, Mossoró, v. 6, n. 3, p.252-257, 2011. Disponível em: http://www.gvaa.com.br/revista/index.php/RVADS/article/view/788/pdf_328. Acesso em: 16 dez. 2015.

REZENDE, G. M.; COSTA, N. D.; DIAS, R. C. S. Clima. In: Sistema de produção de melancia. EMBRAPA/SEMIÁRIDO. Disponível em https://sistemasdeproducao.cnptia.embrapa.br/FontesHTML/Melancia/SistemaProducaoMel ancia/clima.htm>. Acesso em: 23 mai. 2017.

SANTOS, G. R.; LEÃO, E. U.; CASTRO, H. G.; NASCIMENTO, I. R.; SARMENTO, R. A.; SARMENTO-BRUM, R. B. C. Crestamento gomoso do caule da melancia: etiologia, epidemiologia e medidas de controle. Journal of Biotechnology and Biodiversity, Gurupi, v. 2, n. 2 p.52-58, 2011. Disponível em: http://revista.uft.edu.br/index.php/JBB/article/view/229/163. Acesso em: 16 dez. 2015.

TAIZ, L.; ZEIGER, E. Fisiologia vegetal. 5. ed. Porto Alegre: Artmed, 2013. 918 p.

Cultura Agronômica, Ilha Solteira, v.26, n.3, p.251-264, 2017 
TORRES, S. B. Germinação e desenvolvimento de plântulas de melancia em função da salinidade. Revista Brasileira de Sementes, Londrina, v. 29, n. 3, p.77-82, 2007. Disponível em: http://www.scielo.br/pdf/rbs/v29n3/a10v29n3.pdf. Acesso em: 16 dez. 2015. 